\title{
Structural and mechanistic investigations on Salmonella typhimurium acetate kinase (AckA): identification of a putative ligand binding pocket at the dimeric interface
}

Sagar Chittori ${ }^{1,3}$, Handanahal S Savithri ${ }^{2}$ and Mathur RN Murthy ${ }^{1 *}$

\begin{abstract}
Background: Bacteria such as Escherichia coli and Salmonella typhimurium can utilize acetate as the sole source of carbon and energy. Acetate kinase (AckA) and phosphotransacetylase (Pta), key enzymes of acetate utilization pathway, regulate flux of metabolites in glycolysis, gluconeogenesis, TCA cycle, glyoxylate bypass and fatty acid metabolism.
\end{abstract}

Results: Here we report kinetic characterization of S. typhimurium AckA (StAckA) and structures of its unliganded (Form-I, $2.70 \AA$ resolution) and citrate-bound (Form-II, $1.90 \AA$ resolution) forms. The enzyme showed broad substrate specificity with $k_{\text {cat }} / K_{m}$ in the order of acetate $>$ propionate $>$ formate. Further, the $K_{m}$ for acetyl-phosphate was significantly lower than for acetate and the enzyme could catalyze the reverse reaction (i.e. ATP synthesis) more efficiently. ATP and $\mathrm{Mg}^{2+}$ could be substituted by other nucleoside 5/-triphosphates (GTP, UTP and CTP) and divalent cations $\left(\mathrm{Mn}^{2+}\right.$ and $\left.\mathrm{CO}^{2+}\right)$, respectively. Form-I StAckA represents the first structural report of an unliganded AckA. StAckA protomer consists of two domains with characteristic $\beta \beta \beta a \beta a \beta a$ topology of ASKHA superfamily of proteins. These domains adopt an intermediate conformation compared to that of open and closed forms of ligand-bound Methanosarcina thermophila AckA (MtAckA). Spectroscopic and structural analyses of StAckA further suggested occurrence of inter-domain motion upon ligand-binding. Unexpectedly, Form-II StAckA structure showed a drastic change in the conformation of residues 230-300 compared to that of Form-I. Further investigation revealed electron density corresponding to a citrate molecule in a pocket located at the dimeric interface of Form-॥ StAckA. Interestingly, a similar dimeric interface pocket lined with largely conserved residues could be identified in Form-I StAckA as well as in other enzymes homologous to AckA suggesting that ligand binding at this pocket may influence the function of these enzymes.

Conclusions: The biochemical and structural characterization of StAckA reported here provides insights into the biochemical specificity, overall fold, thermal stability, molecular basis of ligand binding and inter-domain motion in AckA family of enzymes. Dramatic conformational differences observed between unliganded and citrate-bound forms of StAckA led to identification of a putative ligand-binding pocket at the dimeric interface of StAckA with implications for enzymatic function.

Keywords: Acetate metabolism, AckA-Pta pathway, Acetate and Sugar Kinases/Heat shock cognate (Hsc) 70/Actin (ASKHA) superfamily, Conformational rearrangement, Enzyme regulation

\footnotetext{
* Correspondence: mrn@mbu.iisc.ernet.in

${ }^{1}$ Molecular Biophysics Unit, Indian Institute of Science, Bangalore, Karnataka 560012, India

Full list of author information is available at the end of the article
} 


\section{Background}

Bacteria respond to frequent changes in their environment by activating metabolic pathways that allow conversion of available nutrients into metabolites of central pathways. Utilization of acetate as a source of carbon and energy requires its initial activation to acetyl-CoA [1-3]. Sequential activities of acetate kinase (AckA, EC 2.7.2.1) and phosphotransacetylase (Pta, EC 2.3.1.8) result in the interconversion of ATP, acetate and CoA to ADP, acetyl-CoA and orthophosphate via acetylphosphate $[4,5]$. In addition to being an important pathway for carbon flow, the AckA-Pta activity might control the cellular concentration of acetyl-CoA and acetylphosphate, which serve as important metabolic intermediates. Acetyl-CoA plays a central role in carbon metabolism [2,3], while acetyl-phosphate acts as a global signal that regulates the function of several proteins involved in flagella biosynthesis and assembly, biofilm development, colonic acid biosynthesis and type-I pilus assembly [6,7]. Studies on AckA from several organisms have shown that the enzyme is also important for xylose metabolism, phosphoryl transfer to enzyme-I of the phosphoenolpyruvate: glucose phosphotransferase system, periplasmic binding proteins and response regulator proteins of two-component systems [8-11].

Enzymes catalyzing transfer of phosphate group include wide-spread protein folds responsible for several indispensable cellular roles including signal transduction, molecular regulation and metabolic functions [12]. Acetate kinase catalyzes reversible transfer of a $\gamma$ phosphate from ATP to acetate in the presence of a divalent metal ion [9]. Similarly, propionate and butyrate kinases utilize propionate and butyrate, respectively, as preferred substrates for phosphoryl transfer from ATP to acceptor ligands $[13,14]$. These enzymes are hereafter referred to as acetokinase family of enzymes (Pfam: PF00871; SCOP: 53080). Extensive structural and functional studies have been carried out for AckA from the archean Methanosarcina thermophila [15,16]. An earlier study on AckA from E. coli suggested that in addition to its cognate substrate acetate, it could also phosphorylate analogous short-chain fatty acids (SCFAs) such as propionate and butyrate [5]. However, in another study, AckAs from E. coli and S. typhimurium, which share $98 \%$ sequence identity, were found to be inactive with respect to propionate and butyrate [9]. In the present study, we report the biochemical characterization and structures of $S$. typhimurium AckA (StAckA, NCBI accession: NP_461279.1, residues: 400, molecular mass: $43.3 \mathrm{kDa}$ ) in two crystal forms at $2.70 \AA$ (apo, Form-I) and $1.90 \AA$ (citrate-bound, Form-II) resolutions. Sequence and structure-based comparisons with homologous enzymes were carried out with the view of understanding their biochemical specificity, overall fold, stability, active site geometry, domain motion and plausible regulation.

\section{Methods}

\section{Enzymatic characterization}

Recombinant StAckA (residues: 415, molecular mass: $45.0 \mathrm{kDa}$ ), cloned into the pRSET C vector, was overexpressed in E. coli and purified using Ni-NTA affinity and gel-filtration chromatography as reported earlier [17]. Biochemical activity of StAckA was examined by two different methods depending on the direction of the reaction (acetyl-phosphate or ATP synthesis) [5,9]. Acetylphosphate synthesis was monitored by coupling the reaction to the oxidation of $\mathrm{NADH}$ in an enzymecoupled reaction using pyruvate kinase (PK) and lactate dehydrogenase (LDH). The standard assay reaction mixture of $0.5 \mathrm{ml}$ contained $50 \mathrm{mM}$ HEPES- $\mathrm{NaOH} \mathrm{pH} 7.5$, $20 \mathrm{mM}$ sodium-acetate, $1 \mathrm{mM}$ ATP, $10 \mathrm{mM} \mathrm{MgCl}_{2}$, $5 \mathrm{mM}$ phosphoenolpyruvate, $0.25 \mathrm{mM} \mathrm{NADH}, 15$ units of PK and 20 units of LDH. In the reverse reaction, ATP synthesis was monitored by coupling the reaction to the reduction of NADP in an enzyme-coupled reaction using hexokinase (HK) and glucose-6-phosphate dehydrogenase (G6PD). The standard reaction mixture of $0.5 \mathrm{ml}$ contained $50 \mathrm{mM}$ HEPES-NaOH pH 7.5, $10 \mathrm{mM}$ acetylphosphate, $1 \mathrm{mM}$ ADP, $10 \mathrm{mM} \mathrm{MgCl}$, $5 \mathrm{mM}$ glucose, 1 mM NADP, 10 units each of HK and G6PD. In both the cases, the reaction was initiated by addition of the enzyme and monitored for $10 \mathrm{~min}$ at $340 \mathrm{~nm}$. All enzymatic experiments were performed in triplicates at $37^{\circ} \mathrm{C}$. The enzyme could be stored for 15 days at $4^{\circ} \mathrm{C}$ without any significant loss of activity. Kinetic constants for StAckA were determined by fitting the initial velocity versus substrate concentration (six data points covering 0.1-10 $K_{m}$ ) to the Michaelis-Menten equation using GraphPad Prism software (Table 1). Metal requirement of StAckA was examined using the method described by Rose et al. [5]. Briefly, the reaction of the product acetyl-phosphate with neutral hydroxylamine leading to the formation of acetyl-hydroxamate was followed spectrophotometrically, by estimating the formation of a colored complex (ferric-hydroxamate, $\lambda_{\max }=540 \mathrm{~nm}$ ) in the presence of ferric ions. Putative StAckA inhibitors were tested by incubation $\left(15 \mathrm{~min}\right.$ at $\left.25^{\circ} \mathrm{C}\right)$ of the enzyme with the compound prior to kinetic measurements.

\section{Spectroscopic studies}

Circular dichroism (CD) spectra of StAckA in the presence of various ligands were recorded using a JASCO J715 spectropolarimeter. The protein concentration was kept at $0.5 \mathrm{mg} \mathrm{ml}^{-1}$ in $5 \mathrm{mM}$ HEPES-NaOH pH 7.5 and $20 \mathrm{mM} \mathrm{NaCl}$ in a cell with a path length of $0.1 \mathrm{~mm}$. Thermal denaturation was monitored by recording the $\mathrm{CD}$ profile at a suitable wavelength from 20 to $95^{\circ} \mathrm{C}$ with 
Table 1 Kinetic constants of StAckA catalyzed reaction

\begin{tabular}{|c|c|c|c|c|c|c|}
\hline Ligand & $K_{m}(\mathrm{mM})$ & $V_{\max }\left(\mu \mathrm{mol} \min ^{-1} \mathrm{mg}^{-1}\right)$ & $k_{\text {cat }}\left(\mathrm{s}^{-1}\right)$ & $k_{c a t} / K_{m}\left(\mathrm{~s}^{-1} \mathrm{mM}^{-1}\right)$ & & \\
\hline Formate & $13.5 \pm 0.3$ & $1180 \pm 20$ & $880 \pm 105$ & $68 \pm 15$ & & \\
\hline ATP (formate) ${ }^{a}$ & $0.085 \pm 0.010$ & $1160 \pm 10$ & $870 \pm 120$ & $10240 \pm 80$ & & \\
\hline Acetate & $1.2 \pm 0.1$ & $1560 \pm 18$ & $1180 \pm 75$ & $985 \pm 62$ & & \\
\hline $\operatorname{ATP}_{\text {(acetate) }}{ }^{a}$ & $0.070 \pm 0.005$ & $1550 \pm 10$ & $1170 \pm 85$ & $16860 \pm 50$ & & \\
\hline Propionate & $11.2 \pm 0.1$ & $1250 \pm 12$ & $940 \pm 85$ & $85 \pm 10$ & & \\
\hline ATP $_{\text {(propionate) }}{ }^{a}$ & $0.075 \pm 0.004$ & $1230 \pm 40$ & $900 \pm 135$ & $11350 \pm 50$ & & \\
\hline Acetyl-phosphate & $0.28 \pm 0.04$ & $2350 \pm 30$ & $1764 \pm 25$ & $6300 \pm 45$ & & \\
\hline ADP & $0.100 \pm 0.003$ & $2340 \pm 20$ & $1750 \pm 65$ & $17645 \pm 10$ & & \\
\hline Nucleotide ${ }^{b}$ & ATP & GTP & UTP & CTP & & \\
\hline$K_{m}(\mathrm{mM})$ & $0.070 \pm 0.005$ & $0.078 \pm 0.027$ & $0.0960 \pm 0.058$ & $0.088 \pm 0.042$ & & \\
\hline$V_{\max }\left(\mu \mathrm{mol} \mathrm{min}^{-1} \mathrm{mg}^{-1}\right)$ & $1560 \pm 18$ & $1475 \pm 25$ & $1185 \pm 22$ & $950 \pm 30$ & & \\
\hline Metal $^{\mathrm{c}}$ & $\mathrm{Mg}^{2+}$ & $\mathrm{Mn}^{2+}$ & $\mathrm{Co}^{2+}$ & $\mathrm{Ni}^{2+}$ & & \\
\hline$[M]^{d}$ & $1.0 \pm 0.2$ & $1.10 \pm 0.6$ & $2.30 \pm 0.3$ & $3.50 \pm 1.0$ & & \\
\hline$V_{\max }\left(\mu \mathrm{mol} \mathrm{min}^{-1} \mathrm{mg}^{-1}\right)$ & $1560 \pm 18$ & $1590 \pm 30$ & $250 \pm 25$ & $70 \pm 40$ & & \\
\hline Inhibition & Citrate & Succinate & $a-K G$ & 2,4-DAB & 2-KB & Malate \\
\hline$[1](m M)^{e}$ & $63 \pm 15$ & $75 \pm 20$ & $7 \pm 1.8$ & $5 \pm 2.2$ & $3 \pm 1.3$ & $1 \pm 0.5$ \\
\hline$V_{a p p}\left(\mu \mathrm{mol} \mathrm{min}^{-1} \mathrm{mg}^{-1}\right)^{f}$ & $1400 \pm 80$ & $1415 \pm 65$ & $900 \pm 70$ & $650 \pm 85$ & $340 \pm 50$ & $175 \pm 95$ \\
\hline
\end{tabular}

a rate of $1^{\circ} \mathrm{C} \mathrm{min}{ }^{-1}$ rise in temperature in a peltier controlled cell holder (JASCO). To study the effect of ligand binding on thermal stability, protein samples were preincubated for $1 \mathrm{~h}$ with the selected ligand (at a concentration close to their $K_{m}$ values) prior to denaturation studies using CD.

The intrinsic fluorescence of AckA was examined using a Hitachi F-200 fluorimeter and a $1 \mathrm{~cm}$ path length cuvette with $\sim 1 \mu \mathrm{M}$ enzyme in a total volume of $250 \mu \mathrm{l}$ buffer containing $50 \mathrm{mM}$ HEPES- $\mathrm{NaOH} \mathrm{pH}$ 7.5 and $200 \mathrm{mM} \mathrm{NaCl}$. Enzyme was titrated with the selected ligand (at a concentration close to their $K_{m}$ values) and the fluorescence spectra were measured after an incubation time of $10 \mathrm{~min}$.

\section{Structure refinement and validation: $a b$-initio model building of residues 230-300 in Form-II StAckA}

Crystallization, X-ray diffraction data collection and initial phase determination of both the StAckA crystal forms have been reported earlier [17]. Interestingly, residues 230-300 (hereafter referred to as the "variable segment") of Form-II were found to be in a conformation completely different from that of Form-I. These residues were modeled ab-initio using COOT [18]. Briefly, modeling of the variable segment was initiated from both ends of the variable segment. This allowed construction of residues 230-237 and 295-300 in the A-subunit and 230-264 and 277-300 in the B-subunit of Form-II StAckA. Interestingly, unlike Form-I, Cys286 of the Bsubunit was found to make an intra-subunit disulfide bond with Cys36. Inspection of the electron density map at Cys36 of A-subunit suggested that a similar disulfide bond is formed in this subunit also. Residues 279-288 of A-subunit could be built around the disulfide bond. Subsequent refinement of the model using REFMAC5 [19] led to further improvement of the electron density map which allowed tracking of the main-chain corresponding to residues 245-246, 277-278 and 289-294 of the A-subunit. Residues 238-244 and 271-276 of Asubunit and residues 265-276 of B-subunit could not be built and are probably disordered. The disordered segments mostly belong to loop regions modeled in Form-I StAckA. Higher B-factors for the variable segment when compared to the rest of the polypeptide reflect the inherent flexibility of this region (data not shown). In the final structure, significant electron density is observed for the modeled residues of the variable segment (Additional file 1: Figure S1). These residues of the variable segment are also well restrained to standard bond distances and angles with 91.5 and 8.5\% occupying the most favored and additionally allowed regions, respectively, of the Ramachandran plot. Details of structure 
refinement and validation statistics for both the crystal forms of StAckA are summarized in Table 2.

\section{Sequence and structural analyses}

Sequence homologs of StAckA were identified in the Swiss-Prot database [20]. DALI [21] server was used for the identification of homologous structures. Multiple sequence alignment was achieved using ClustalW [22] and a graphical representation of the alignment as well as superposition of the secondary structures was obtained using ESPript [23]. The Protein Interfaces, Surfaces and Assemblies (PISA) [24] and Protorp [25] servers were used for the analysis of dimeric interfaces. HingeProt [26] and ElNeMo [27] servers were used to analyze plausible conformational dynamics. Computed Atlas of Surface Topography of proteins (CASTp) [28] server was used for locating potential ligand-binding cavities. Ligands were modeled at the active site of StAckA by comparison with the ligand bound structure of MtAckA (PDB:1TUY) [16], and energy minimized using the CNS program [29]. Molecular figures were created with PyMOL (http://www.pymol.org/).

\section{Accession codes}

The atomic coordinates and structure factors for the apo (Form-I, PDB:3SLC) and citrate-bound (Form-II, PDB:3SK3) forms of StAckA have been deposited with RCSB.

\section{Results}

\section{Acetokinase family of enzymes in prokaryotes}

Search for StAckA homologs yielded more than 300 non-redundant sequences belonging to the acetokinase family of enzymes that includes acetate, propionate and butyrate kinases. Acetate and propionate kinases share significant sequence identity $(\sim 40 \%)$ and both groups possess only a low level of identity with butyrate kinases ( $20 \%$, Figure 1). Salmonella typhimurium genome codes for three homologs of acetokinase family; namely AckA (acetate kinase), TdcD (propionate kinase) and PduW (putative acetate/propionate kinase). StAckA shares sequence identities of $41 \%$ and $40 \%$ with $S t \mathrm{TdcD}$ and StPduW, respectively. Based on sequence analysis, an enzyme corresponding to PduW of S. typhimurium could not be identified in the closely related $E$. coli. In both

Table 2 Structure refinement and validation statistics

\begin{tabular}{|c|c|c|}
\hline Parameter & Form-I (unliganded) & Form-II (citrate-bound) \\
\hline Resolution range $(\AA)^{\text {a }}$ & $50.0-2.70(2.80-2.70)$ & $50.0-1.90(1.97-1.90)$ \\
\hline \multicolumn{3}{|l|}{ No. of atoms } \\
\hline Protein / Water / EDO / CIT b & $11748 / 204 / 16 /-$ & $5838 / 442 / 16 / 13$ \\
\hline \multicolumn{3}{|l|}{ R-factors (\%) ${ }^{c}$} \\
\hline$R_{\text {work }} / R_{\text {free }}$ & $22.1 / 28.3$ & $18.9 / 22.4$ \\
\hline Correlation coefficient (\%) $^{d}$ & 85.4 & 94.1 \\
\hline Wilson B-factor $\left(\AA^{2}\right)$ & 53.4 & 41.9 \\
\hline \multicolumn{3}{|l|}{ Average B-factor $\left(\AA^{2}\right)$} \\
\hline Protein / Water / EDO / CIT & $44.7 / 10.4 / 45.8 /-$ & 36.1 / 44.2 / 56.4 / 33.9 \\
\hline \multicolumn{3}{|l|}{ RMS deviation } \\
\hline Bond length $(\AA)$ & 0.006 & 0.014 \\
\hline Bond angle $\left(^{\circ}\right)$ & 0.977 & 1.414 \\
\hline Dihedral angle $\left({ }^{\circ}\right)$ & 5.024 & 5.908 \\
\hline Chiral-center restraints $\left(\AA^{3}\right)$ & 0.066 & 0.098 \\
\hline General planes $(\AA ̊)$ & 0.003 & 0.006 \\
\hline Coordinate error: Luzzati (Å) & 0.412 & 0.237 \\
\hline \multicolumn{3}{|c|}{ Residues in Ramachandran map (\% / number) } \\
\hline Most favoured region & $89.1 / 1,228$ & $90.9 / 610$ \\
\hline Allowed region & $10.9 / 150$ & $8.8 / 59$ \\
\hline Generously allowed region & $0 / 0$ & $0.3 / 2$ \\
\hline Disallowed region & $0 / 0$ & $0 / 0$ \\
\hline
\end{tabular}

Refinement and validation statistics are from REFMAC5 [19] and PROCHECK [37].

${ }^{a}$ Values for the highest resolution shell are given in parentheses.

${ }^{\mathrm{b}} \mathrm{EDO}$ and CIT refer to ethylene glycol and citrate, respectively.

${ }^{c} R_{\text {work }}=\Sigma\left(\left|F_{\text {obs }}\right|-\left|F_{\text {calc }}\right|\right) / \Sigma\left|F_{\text {obs }}\right| ; R_{\text {free }}$ was calculated similarly by using $5 \%$ of the reflections that were excluded from the refinement.

${ }^{\mathrm{d}}$ Correlation coefficient $=\sum\left(\mathrm{F}_{\mathrm{o}} \mathrm{F}_{\mathrm{c}}-<\mathrm{F}_{\mathrm{o}}><\mathrm{F}_{\mathrm{c}}>\right) /\left[\left(\sum\left(\mathrm{F}^{2}{ }_{\mathrm{o}}-<\mathrm{F}_{\mathrm{o}}>^{2}\right)\left(\sum \mathrm{F}^{2}{ }_{\mathrm{c}}-<\mathrm{F}_{\mathrm{c}}>^{2}\right)\right]^{1 / 2}\right.$. 


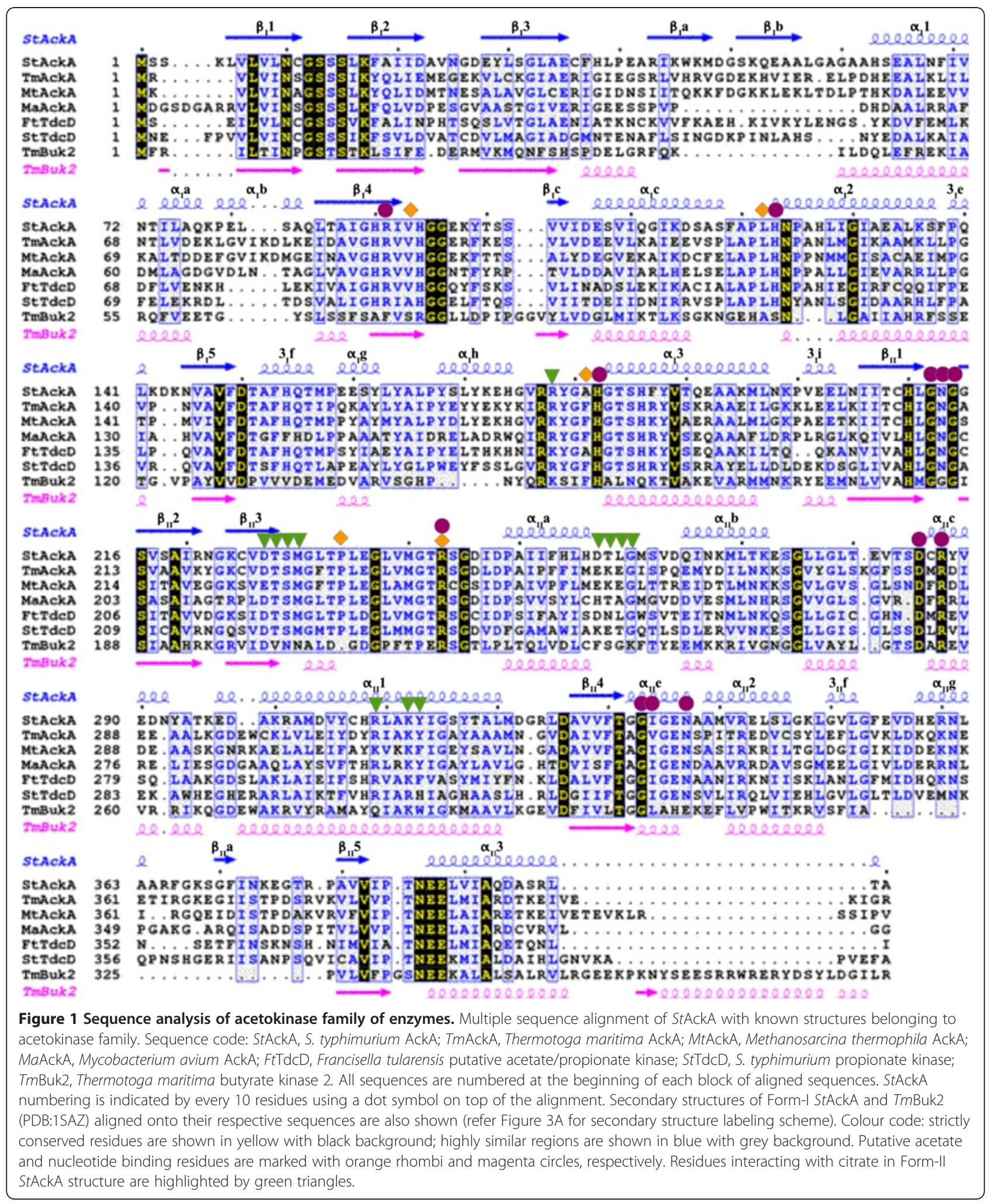

S. typhimurium LT2 and E. coli $\mathrm{K} 12$, a gene corresponding to a butyrate kinase could not be detected, suggesting differences in utilization of SCFA in microorganisms.
Enzymatic specificity of the recombinant StAckA

Earlier studies on SCFA specificity of AckAs have led to conflicting reports $[5,9]$. In the present study, the 
recombinant StAckA was purified to homogeneity using Ni-NTA affinity chromatography followed by gel-filtration. The preliminary enzymatic assay with acetate, ATP and $\mathrm{Mg}^{2+}$ as substrates showed that the StAckA catalyzed reaction follows Michaelis-Menten kinetics with $\mathrm{pH}$ and temperature optima in the range of 7.2-7.5 and $35-37^{\circ} \mathrm{C}$, respectively (Figure 2). This highly purified, stable and active preparation of StAckA was further used to examine the kinetics of phosphoryl transfer reaction from ATP to various SCFA substrates viz. formate, acetate, propionate and butyrate. It was observed that StAckA could catalyze phosphate transfer at significant rate from ATP to formate, acetate and propionate (Table 1). However, butyrate was not found to be a suitable substrate. In addition, the presence of butyrate at equimolar concentration reduced the catalytic rate of acetate utilization by $40 \%$, which might suggest competitive binding of butyrate at the SCFA binding site. Further, kinetic analysis showed that the $K_{m}$ is nearly 10 times lower for acetate when compared to formate or propionate (Table 1 ). As maximum velocity and catalytic turnover numbers $\left(k_{\text {cat }}\right)$ were found to be similar for these substrates, the catalytic efficiency $\left(k_{c a t} / K_{m}\right)$ for acetate was $\sim 10$ times higher than for formate or propionate, indicating that acetate is the preferred substrate. Noticeably, the enzyme showed similar $K_{m}$ and $k_{c a t}$ values for ATP when either formate, acetate or propionate was used as the SCFA substrate (Table 1). Further kinetic characterization revealed that StAckA catalyzes the reverse reaction i.e. phosphoryl transfer from acetylphosphate to ADP much more efficiently (Table 1). The $K_{m}$ for ADP and ATP are comparable whereas the $K_{m}$ for acetyl-phosphate is significantly lower compared to that for acetate.

The biochemical investigations were further extended for assessment of nucleotide analogs as phosphoryl donors in StAckA catalyzed reaction. These kinetic assays showed that apart from ATP and GTP, consistent with reports from Fox \& Roseman [9], StAckA could also utilize pyrimidine bases such as UTP and CTP with comparable affinities (Table 1). Activity of StAckA was found to be completely abolished in the presence of EDTA (5 times $\mathrm{Mg}^{2+}$ concentration) or in the absence of suitable divalent ions, suggesting that divalent cations are essential for the catalysis. In addition to $\mathrm{MgCl}_{2}$ $\left(V_{\max }=100 \%\right)$, the enzyme could be activated by $\mathrm{MnCl}_{2}$ $\left(V_{\max }=100 \%\right), \mathrm{CoCl}_{2}\left(V_{\max }=15 \%\right)$ and to a minor extent by $\mathrm{NiCl}_{2}\left(V_{\max }=5 \%\right)$ (Table 1$)$. However, several other divalent $\left(\mathrm{CaCl}_{2}, \mathrm{FeCl}_{2}, \mathrm{CuCl}_{2}, \mathrm{ZnCl}_{2}, \mathrm{CdCl}_{2}\right.$ and $\mathrm{HgCl}_{2}$ ) and monovalent ( $\mathrm{LiCl}$ or $\mathrm{CsCl}$ ) ions failed to activate the enzyme. A divalent metal-ion ratio of 1:1 with ATP appeared to be optimal while a large excess (>25 times) of $\mathrm{Mg}^{2+}$ relative to ATP was found to reduce the catalytic rate, which might suggest that free $\mathrm{Mg}^{2+}$ could inhibit the binding of catalytically competent ATP- $\mathrm{Mg}^{2+}$ complex to the enzyme.

\section{Crystal structure of Form-I StAckA}

Crystal structures of two archeal acetate kinases, from Thermotoga maritima (PDB:2IIR, unpublished results) and Methanosarcina thermophila [15] and one from Mycobacterium avium (PDB:3P4I, unpublished results) have been determined earlier. However, structures of AckA from mesophiles such as S. typhimurium, or the closely related $E$. coli were not available. To obtain molecular insights into the mesophilic AckA, we determined the crystal structure of StAckA at $2.70 \AA$ resolution (Form-I, Figure 3) by molecular replacement using a polyalanine model of the TmAckA (PDB:2IIR, unpublished results) monomer as the search model. The asymmetric unit (ASU) of Form-I StAckA crystal consists of four nearly identical protomers, as indicated by the low root mean square deviations (rmsd) of corresponding $\mathrm{C}_{\alpha}$ atoms (0.43-0.84 $\AA$ for $>350$ target pairs). StAckA protomer consists of 22 helices (160 residues, $41.2 \%$ ), $14 \quad \beta$-strands (77 residues, $19.8 \%$ ) and loop regions (151 residues, 38.9\%; Figures $3 \mathrm{~A}$ and B). As in the homologous archeal enzyme [15], each subunit could be further divided into N-terminal (Domain-I, residues 3-152 and 386-400) and C-terminal (Domain-II, residues 153-385) domains. The $\alpha$-helices present at the
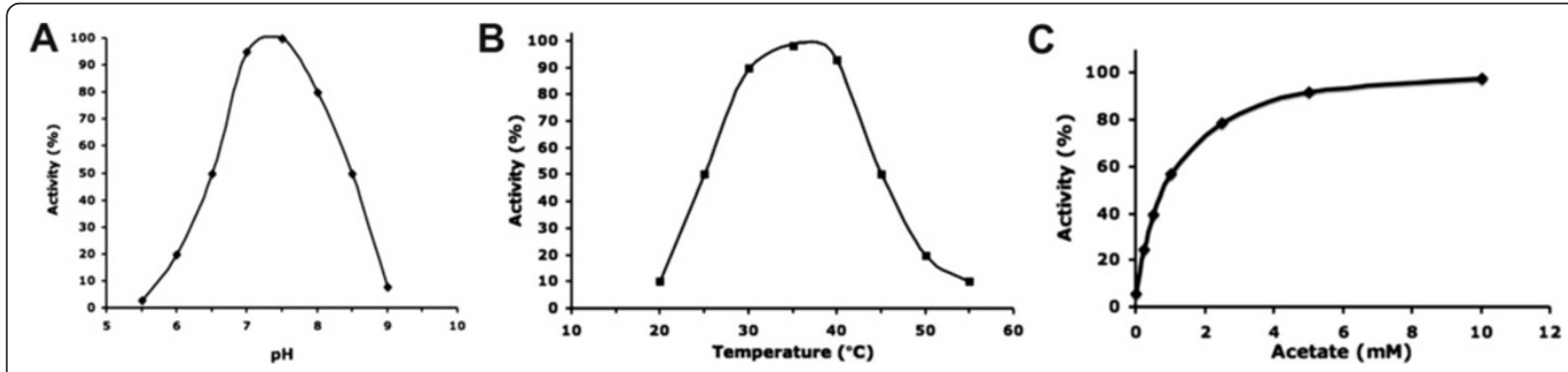

Figure 2 Enzymatic characterization of StAckA. Plot of enzyme activity (\%) at various (A) pH and (B) Temperature values. (C) Profile of saturation kinetics exhibited by StAckA with acetate as substrate. 


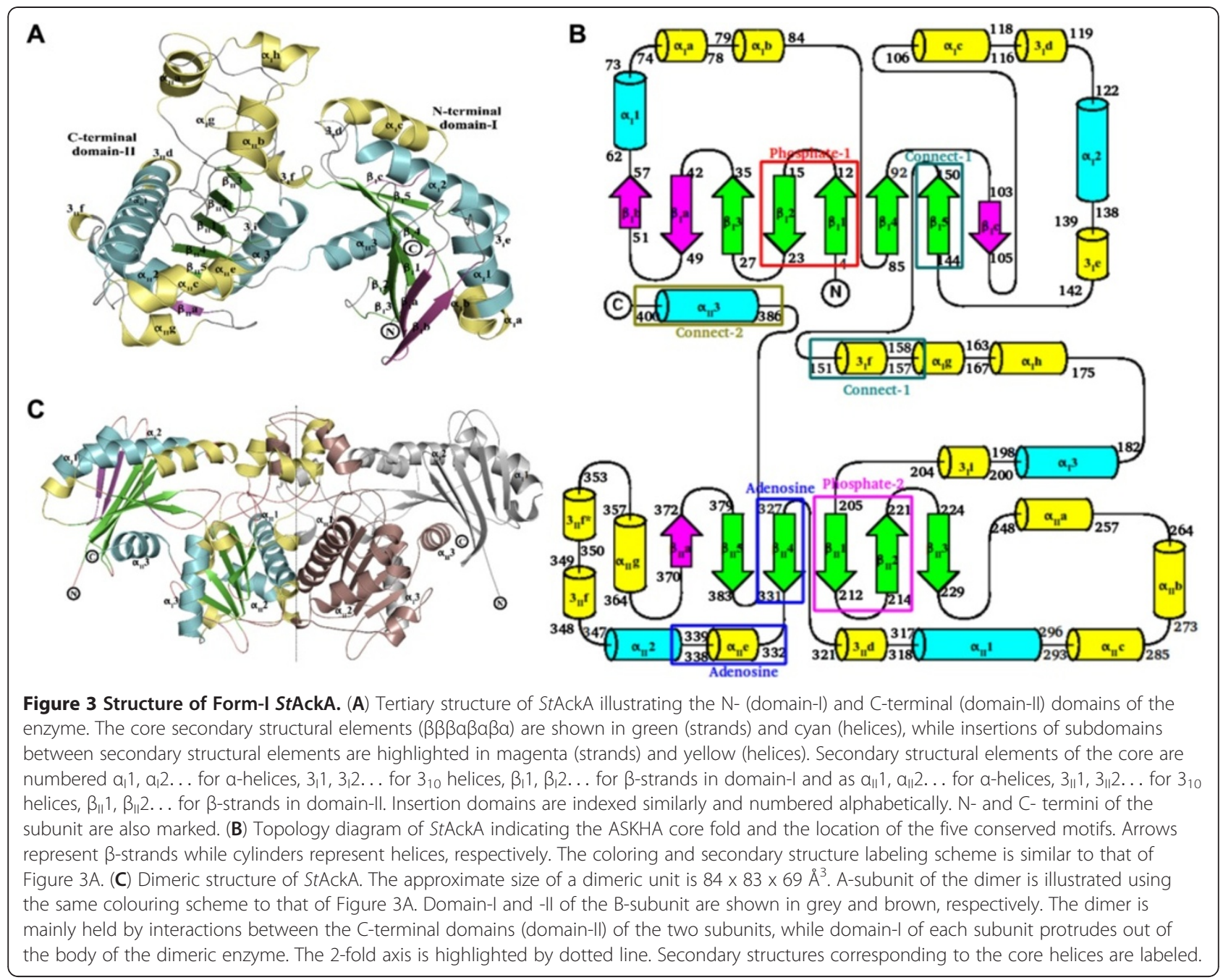

carboxy-terminal ends of both the domains extend to form part of the other domain.

The four subunits of StAckA present in the ASU are further organized as two dimers resembling the dimeric structure of the archeal enzymes [15]. The two dimers of the asymmetric unit could be superposed with $C_{\alpha}$ rmsd of $0.50 \AA$ for 706 target pairs suggesting that the organization of the protomers in the two dimers are essentially identical. The subunits of a dimer are related by nearly perfect non-crystallographic two-fold symmetries (Figure 3C). The accessible surface area (ASA) of an StAckA monomer was found to be $17,920 \AA^{2}$ and upon dimerization approximately $3,061 \AA^{2}$ (17\% of total ASA) per subunit gets buried. Several segments of domain-II $\left(\alpha_{\mathrm{I}} \mathrm{g}, \alpha_{\mathrm{I}} \mathrm{h}, \alpha_{\mathrm{II}} \mathrm{a}, \alpha_{\mathrm{II}} \mathrm{b}, \alpha_{\mathrm{II}} 1\right.$ and $3_{\mathrm{II}} \mathrm{f}$ and $\left.\mathrm{f}^{*}\right)$ contribute to the dimeric interface. A total of approximately 81 residues (20\% of total surface residues), of which $23 \%$ are polar, $53 \%$ are non-polar and $24 \%$ are charged, contribute to the interactions at the interface leading to approximately 23 hydrogen bonds and 8 salt bridges. There are also a few water-mediated hydrogen bonds between the two subunits of the dimer. This analysis indicates a stable dimeric interface.

\section{Active site pocket and specificity determinants}

A cleft between the two domains forms the active site pocket of StAckA. Structural comparison with the ligand-bound MtAckA structures [15,16] allowed identification of residues likely to be important for acetate (Val93, Ala181, Leu122, Pro234 and Arg243), nucleotide (Arg91, His123, His182, Gly212, Asn213, Gly214, Arg243, Asp285, Arg287, Gly333, Ile334 and Asn337) and metalion (Asn10, Lys17, Asp150, Glu387) binding by StAckA. These residues are also conserved in other members of acetokinase family (Figure 1), indicating their shared ligand binding modes and catalytic mechanisms.

As observed from kinetic measurements, StAckA could catalyze phosphoryl transfer to formate, acetate and propionate but not to butyrate (Table 1). Despite several attempts, crystals of ligand bound enzyme could 
not be obtained either by co-crystallization or soaking. Therefore, based on the acetate- $\mathrm{AlF}_{3}$-ADP bound structure of MtAckA [16], formate, acetate, propionate and butyrate were modeled into the active site of the Salmonella enzyme. As anticipated, acetate could be accommodated with favorable interactions (Figure 4A). Although formate could also be accommodated, it made fewer interactions when compared to that of acetate while the additional methyl group of propionate (as compared to acetate) formed a short contact with Val93 of StAckA. This short contact could however be relieved by a small conformational adjustment of Val93 or by pointing the extra methyl-group of propionate towards Ala181, which is a semi-conserved residue and is mostly replaced by phenylalanine in acetokinases (Figures 1 and $4 \mathrm{~A})$. The aromatic ring of this phenylalanine bends away from the active site pocket and thus effectively presents a hydrophobic environment equivalent to that of alanine towards the SCFA binding site (Figure 4A). Similar adjustment with butyrate was not possible as the short contacts with Val93 and Ala181 could not be relieved by small conformational adjustments that would allow the reactive group of butyrate to be oriented appropriately for catalysis.

Similarly, modeling of nucleotides was carried out based on the acetate-AlF - ADP bound structure of $M t$ AckA [16]. The analysis revealed that the enzyme interacts with the nucleotide base mainly by hydrophobic interactions (Figure 4B). Absence of directional ionic interactions with nucleotides could account for the broad nucleotide specificity of the enzyme. Although it is likely that AckA is primarily an ATP-dependent enzyme, the broad specificity will allow other nucleotides also to support acetate utilization.

\section{Ligand-induced conformational changes in StAckA}

Proteins belonging to ASKHA superfamily have been suggested to undergo inter-domain motion upon ligand binding [30-33] (Figure 5A). In the present study, ligand binding to StAckA was examined by monitoring the thermal stability of the enzyme using CD spectroscopy. The unliganded enzyme showed a melting temperature $\left(\mathrm{T}_{\mathrm{m}}\right)$ of $45^{\circ} \mathrm{C}$ at which $50 \%$ of the enzyme was unfolded. An increased $\mathrm{T}_{\mathrm{m}}$ was observed with the addition of
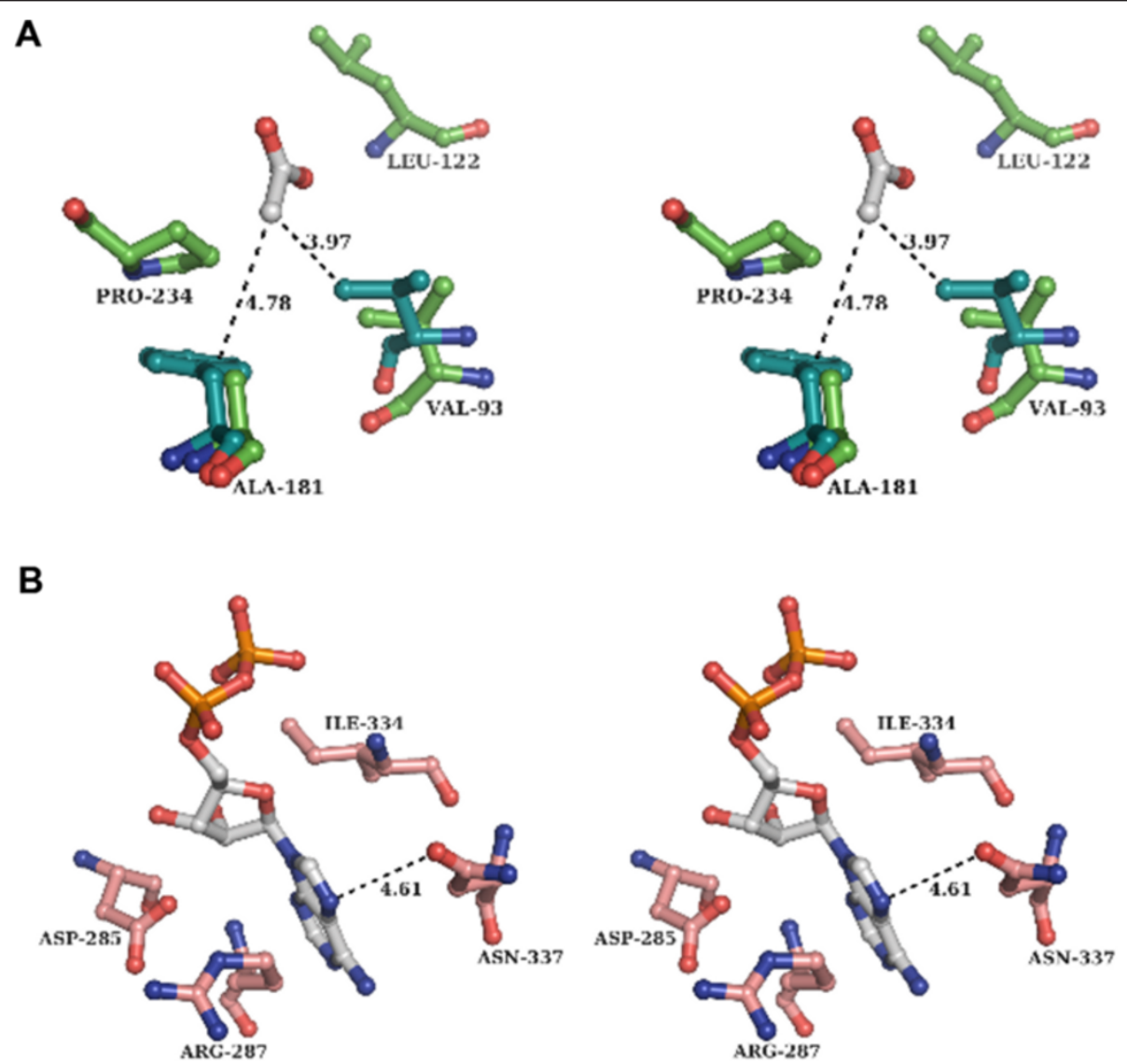

Figure 4 Molecular basis for the substrate and nucleotide specificity of StAckA. (A) Stereo diagram of SCFA binding residues (lime-green) of StAckA with modeled acetate (grey). For comparison, a few superposed residues (teal) of MtAckA are also shown. (B) Stereo diagram of the putative nucleotide-binding residues (salmon-red) of StAckA and modeled ADP (grey). Distances shown with dashed lines are in A. 


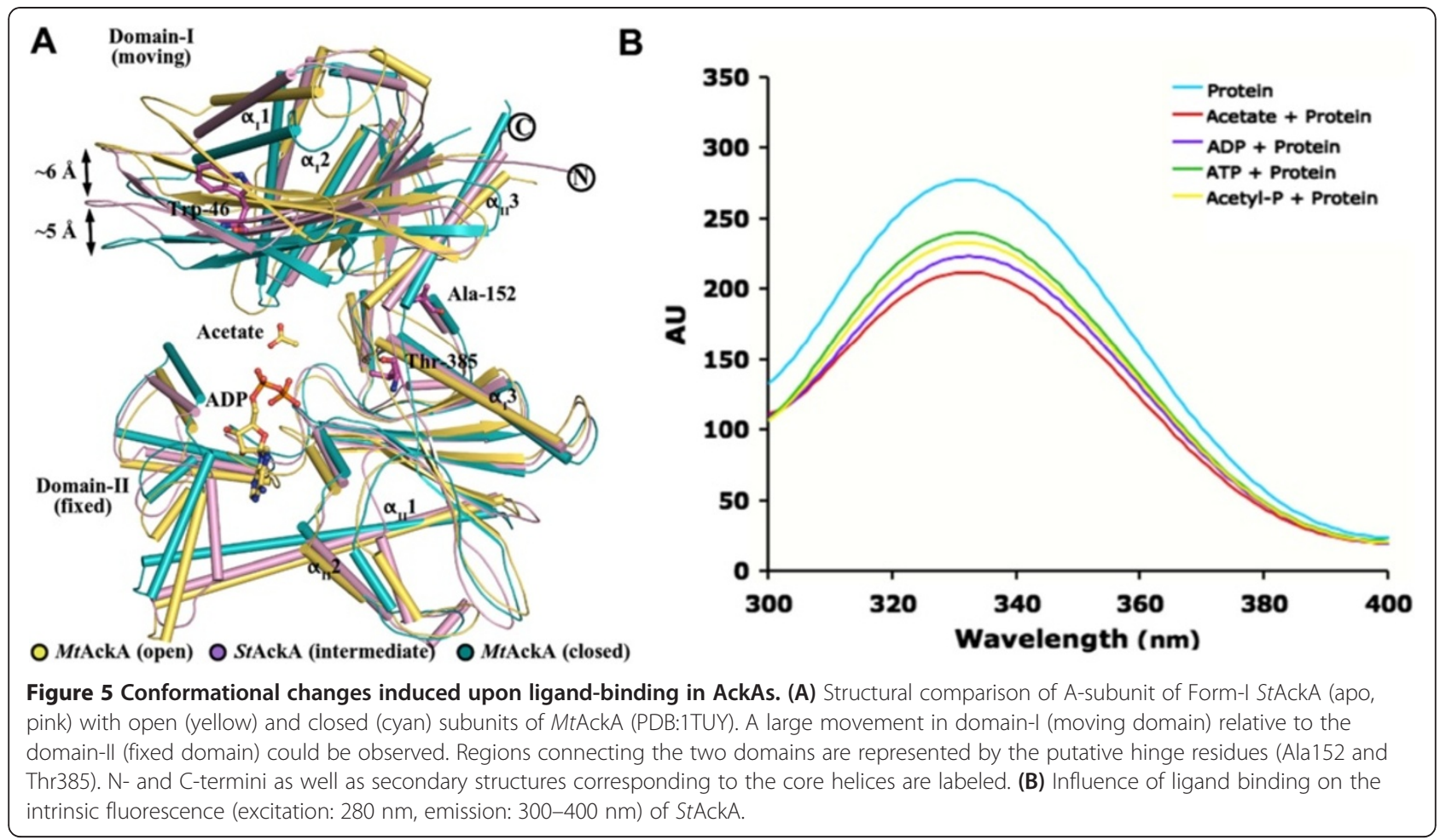

acetate $\left(50^{\circ} \mathrm{C}\right)$, acetyl-phosphate $\left(54^{\circ} \mathrm{C}\right), \operatorname{ADP}\left(52^{\circ} \mathrm{C}\right)$ and $\operatorname{ATP}\left(52^{\circ} \mathrm{C}\right)$, suggesting that the protein becomes more stable upon ligand binding. Noticeably, StAckA contains a single tryptophan (Trp46) residue, which is located in domain-I at a large distance (20 $\AA$ between $C_{\alpha}$ of Trp46 and Asn213, a residue involved in binding of nucleotide phosphates) from the active site. This allows monitoring of conformational transition induced upon ligandbinding by measuring fluorescence quenching due to the change in the tryptophan environment. Intrinsic fluorescence spectra of StAckA recorded in the presence of acetate, acetyl-phosphate, ADP and ATP showed quenching as compared to the unliganded enzyme (Figure 5B), thus indicating that binding of these ligands is likely to result in conformational transitions that may involve inter-domain movement.

\section{Crystal structure of Form-II StAckA}

Another crystal form of StAckA (Form-II) was obtained in the presence of citrate [17]. The structure of this form was determined at $1.90 \AA$ resolution using a polyalanine model of the Form-I StAckA monomer. Although the overall polypeptide fold in these two forms is similar, residues 230-300 (variable segment) were in significantly different conformations in the two subunits of Form-II dimer and these conformations in turn were different from that observed for this segment in Form-I (Figure 6A). Superposition of A- and B-subunits of
Form-II StAckA with the A-subunit of Form-I StAckA excluding the variable segment results in rmsds of $1.03 \AA$ and $1.53 \AA$ for 326 and 313 pairs of $C_{\alpha}$ atoms, respectively (Figure 6B). The variable segment is located between strand $\beta_{\mathrm{II}} 3$ and helix $\alpha_{\mathrm{II}} 1$ (Figures $3 \mathrm{~A}$ and $\mathrm{B}$ ). In the A-subunit of Form-II, residues 230-237 and 247255 are at a location close to the corresponding region of Form-I StAckA (Figure 6B). However, position and conformation of residues 258-270 and 277-294 are completely different from those of Form-I. The segment consisting of residues 230-263 of the B-subunit of Form-II is initially close to the corresponding segment of Form-I but progressively departs from the structure observed in Form-I towards the C-terminal end. Residues 277-287 of B-subunit are close to the active site cleft present between the domains and occupy the space where ligands are expected to bind.

The three conformationally distinct subunits (subunits of Form-I and A- and B-subunits of Form-II) also show variations in the degree of domain closure. B-subunit of Form-II represents the most closed state while Asubunit represents a conformation between those of Form-I and B-subunit of Form-II (data not shown). Despite the large conformational differences in the variable segment and inter-domain closure, structures of other segments are largely retained (Figures 6A and B) and the dimeric nature is preserved in Form-II (Figure 6C). The residues in the variable segment of Form-I are involved 


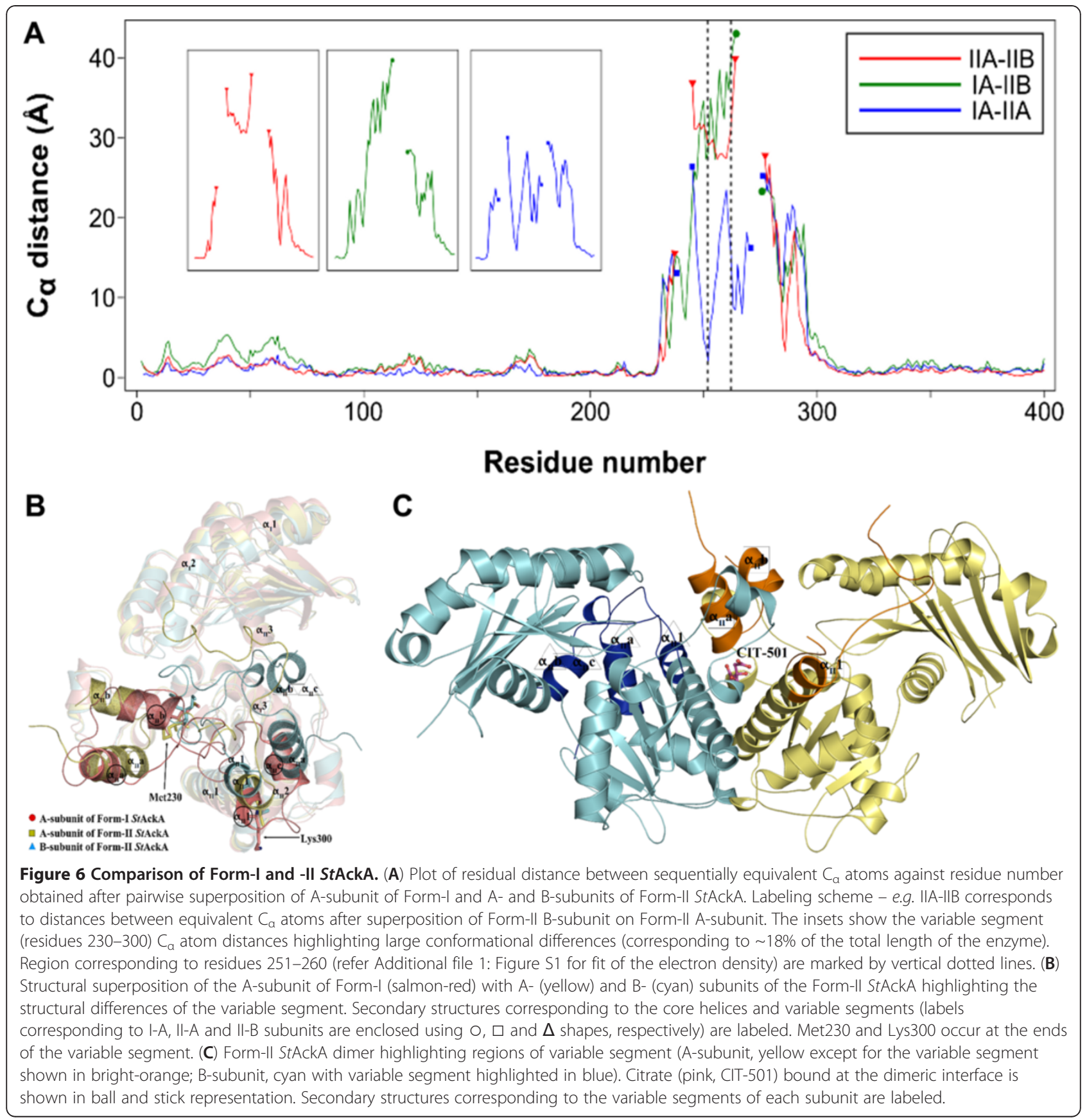

in inter-subunit interactions. This leads to reduction in the buried surface area $\left(1,996 \AA^{2}\right.$ compared to $3,061 \AA^{2}$ of Form-I) and ionic interactions (hydrogen bonds = 12; salt bridges $=13$ compared to 23 and 10 , respectively, of Form-I) of the dimeric interface between the subunits (ASA of Form-II StAckA monomer: 17,235 $\AA^{2}$ ) of Form-II. As the residues of the variable segment are also involved in the formation of active site pocket, Form-II structure is not suitable for binding nucleotides and therefore may represent an inhibited state of the enzyme.
Identification of a putative dimeric interface pocket

Examination of the difference electron density map of Form-II StAckA showed significant uninterpreted density located at the dimeric interface that was distinct from that of the polypeptide chain. Citrate, a component of the crystallization condition, was found to best fit the density (Figure 7) and could be refined with reasonable B-factors (33.9 $\AA^{2}$ ) and occupancy (0.75). Interestingly, only one citrate binds at the dimeric interface resulting in an asymmetric dimer. Citrate occupies a highly 


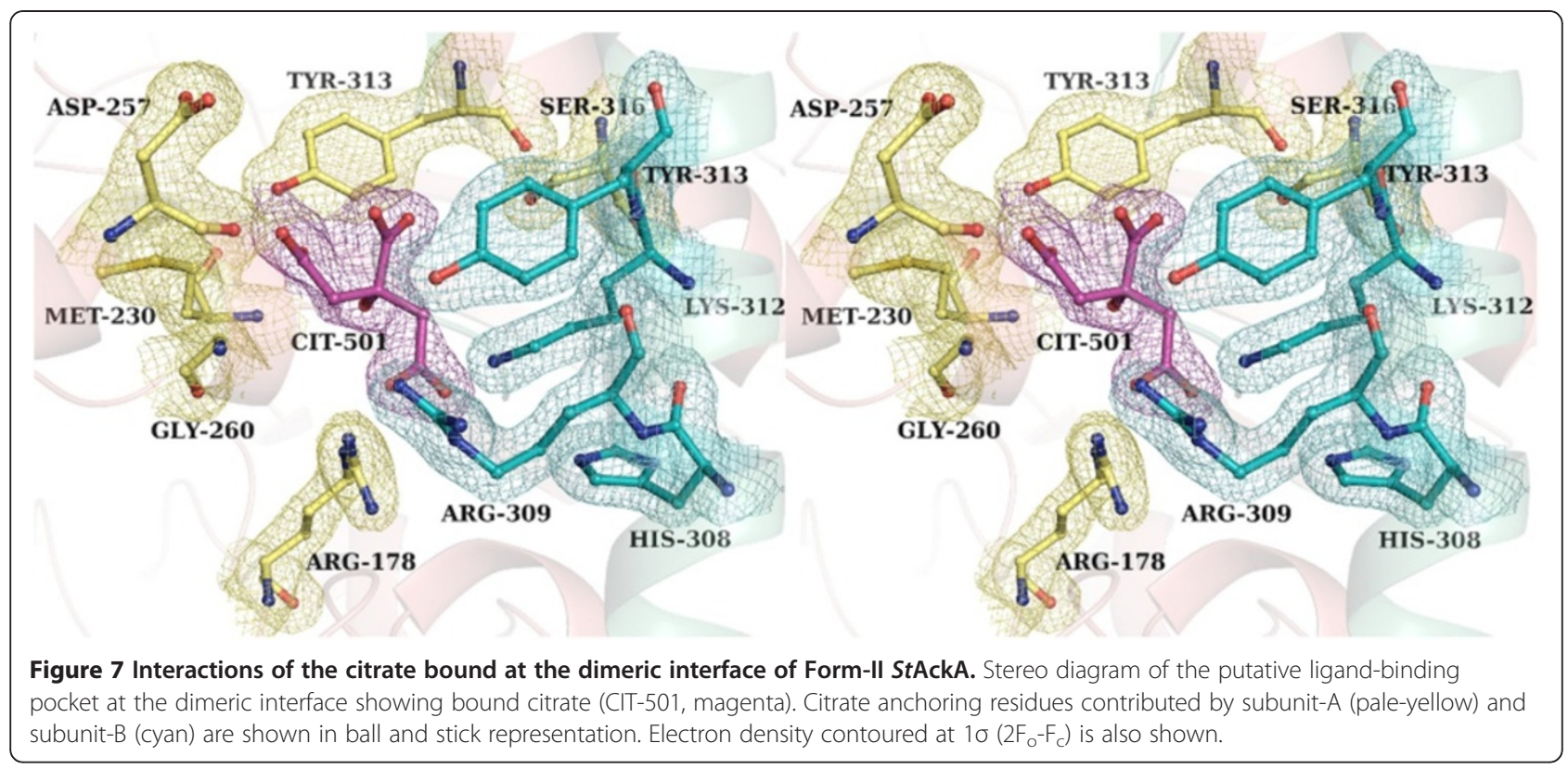

polar and charged environment. It interacts with atoms (distance cutoff: $\leq 5.0 \AA$ ) of residues Arg178, Asp227, Thr228, Ser229, Met230, Asp257, Thr258, Leu259, Gly260, Arg309, Lys312 and Tyr313 of the A-subunit and Arg309, Lys312 and Tyr313 of the B-subunit. Some of the residues that interact with the citrate are from the amino-terminal end of the variable segment and hence the conformational differences between the two subunits observed in the Form-II structure could be due to citrate binding.

Inspection of Form-II StAckA protomer structure revealed a shallow cavity at the site of citrate binding (Figures 8A and B). In the dimeric structure, these cavities coalesce, forming a larger pocket suitable for ligand binding (Figure 8C). Intriguingly, examination of Form-I StAckA as well as other structurally known members of acetokinase family (Table 3 ) revealed a similar cavity at the dimeric interface (Figure $8 \mathrm{C}$ and Additional file 2: Figure S2). As many of the residues (Arg178, Asp227, Met230, Arg309 and Tyr313; StAckA numbering) lining the cavity are highly conserved across acetokinases (indicated by green triangle in Figure 1), the dimeric interface pocket observed for the first time in Form-II StAckA could be involved in binding of a putative ligand that might influence the activity of the enzyme.

\section{Discussion}

\section{Implications to SCFA metabolism}

Acetate kinase is ubiquitously present in bacteria and archea [10] and appears to be absent in humans [34]. As AckA is involved at the junction of carbohydrate and fatty acid metabolism, it might be a suitable target for development of inhibitors [34]. We have earlier structurally and biochemically characterized Salmonella typhimurium propionate kinase (St TdcD) and demonstrated that the enzyme is specific to propionate although could utilize acetate at a 10 times lower rate $[13,35]$. In the present study, we report structural and mechanistic investigations of StAckA. Among the SCFAs tested, acetate was the preferred substrate although the enzyme showed significant activity with formate as well as propionate (Table 1), which is consistent with the physiological function of the enzyme in acetate metabolism. On the other hand, affinity for various nucleotides were comparable (Table 1). Modeling studies revealed that interactions with the nucleotide occur mainly through the base moiety with minor contribution from the phosphates, which is in agreement with the comparable $K_{m}$ obtained for ADP and ATP for StAckA (Table 1). The observed broad specificity of StAckA is suggestive of its primitive origin which might have been crucial for the survival of ancestral cells that functioned with limited resources.

Interestingly, StAckA could catalyze the reverse reaction (ATP formation) more efficiently when compared to the forward reaction (acetyl-phosphate synthesis) (Table 1). This could serve as a major source of energy during anaerobic growth of S. typhimurium. The structure of ADP$\mathrm{AlF}_{3}$-acetate complex of MtAckA $[15,16]$ reveals that the phosphate is likely to bind at a deeper site in the active site pocket with acetyl moiety occupying an exterior site. The phosphate is likely to form significant interactions with the protein and contribute to the higher affinity for acetylphosphate when compared to acetate (Table 1). 


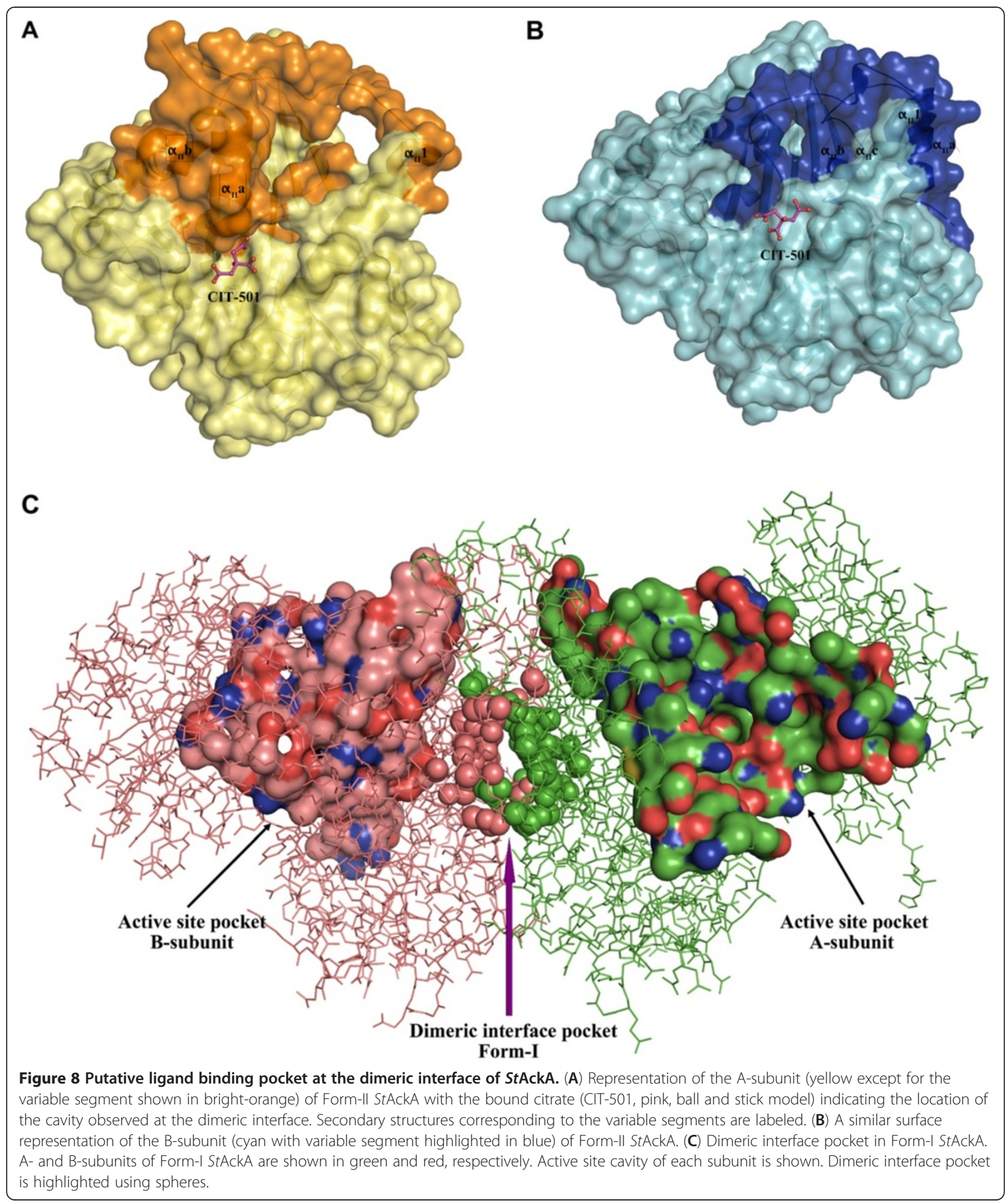

\section{Diversification of AckA fold}

DALI search [21] revealed significant similarities of StAckA with over 100 non-redundant (90\% sequence identity cut-off) structures deposited in the PDB. These structurally similar domains include not only kinases but also several other proteins with diverse functions such as transcriptional regulator ROK family homolog of $E$. coli MLC protein (2GUP/3.9 $\AA / 11 \%)$, O-sialoglycoprotein 
Table 3 Structural features of the dimeric interface pocket identified in acetokinase family of enzymes

\begin{tabular}{|c|c|c|c|c|c|c|}
\hline Protein & PDB code & Identity (\%) ${ }^{a}$ & $\operatorname{RMSD}\left(\AA^{2}\right) / C_{a}$ aligned $^{a}$ & Area $\left(\AA^{2}\right)$ & Volume $\left(\AA^{3}\right)$ & Reference \\
\hline StAckA-I-AB & $3 S L C$ & 100 & $0 / 797$ & 898 & 891 & present study \\
\hline StAckA-I-CD & $3 S L C$ & 100 & $0.59 / 706$ & 848 & 866 & present study \\
\hline StAckA-II-AB b & $3 S K 3$ & 100 & $1.44 / 579$ & - & - & present study \\
\hline MtAckA-AB & $1 \mathrm{G} 99$ & 43 & $1.78 / 676$ & 985 & 1124 & {$[15]$} \\
\hline TmAckA-AB & $2 \| 1 \mathrm{R}$ & 46 & $1.46 / 764$ & 961 & 1128 & unpublished results \\
\hline MaAckA-AB & $3 \mathrm{P} 4 \mathrm{I}$ & 41 & $1.74 / 708$ & 1114 & 1088 & unpublished results \\
\hline FtTdcD-AB & $3 \mathrm{KHY}$ & 45 & $1.45 / 732$ & 933 & 1271 & unpublished results \\
\hline StTdcD-AA' c & $2 \mathrm{E} 1 \mathrm{Y}$ & 41 & $1.19 / 744$ & 922 & 732 & [35] \\
\hline TmBuk2-AF & 1SAZ & 16 & $2.37 / 604$ & 1244 & 1311 & unpublished results $^{d}$ \\
\hline
\end{tabular}

${ }^{a}$ Identity and RMSD correspond to the comparison of the query protein with StAckA Form-I dimer (StAckA-I-AB).

${ }^{\mathrm{b}}$ Due to continuity between the dimeric interface pocket and the active site cavities of A- and B-subunits in Form-II StAckA (Additional file 2: Figure S2C), volume of dimeric interface pocket in Form-II is not well defined.

' StTdcD dimer ( $\mathrm{A}$ ' indicates symmetry relation with $\mathrm{A}$ ) was generated using the crystallographic 2-fold axis.

${ }^{d}$ The originally published paper by Diao and Hasson (2009) has been retracted by the publisher for data ownership issues.

endopeptidase (2IVN/4.2 $\AA / 14 \%$ ), actin (3B63/4.6 $\mathrm{A} /$ $11 \%)$, cell division protein FtsA (1E4G/4.1 $\AA / 11 \%)$, plasmid segregation protein ParM (3IKY/4.2 $\AA / 10 \%)$, diol dehydratase-reactivating factor large subunit (2D0O/ $4.6 \AA / 10 \%)$, activator of 2-hydroxyglutaryl-CoA dehydratase (1HUX/4.3 $\AA / 15 \%)$, glycerol dehydratase reactivase $\alpha$-subunit (1NBW/4.6 $\AA / 12 \%)$, heat shock $70 \mathrm{kDa}$ protein (3FZF/5.4 $\AA / 10 \%)$, rod shape-determining protein MreB (1JCF/4.0 $\AA / 10 \%)$, ethanolamine utilization protein EutJ $(3 \mathrm{H} 1 \mathrm{Q} / 3.8 \AA / 14 \%)$ and a few other proteins of unknown function (corresponding PDB code, rmsd of $\mathrm{C} \alpha$ atoms upon superposition with StAckA, and sequence identity with StAckA are shown in parentheses). This remarkable structural and functional versatility is comparable to that of the well-known TIM-barrel proteins and is consistent with biochemical studies that suggest emergence of AckA fold early in evolution.

Although no overall sequence similarity between Acetate and Sugar Kinases/Heat shock cognate (Hsc) 70/ Actin (ASKHA) superfamily could be detected, these proteins typically bind ATP and contain a duplicated core with $\beta \beta \beta \alpha \beta \alpha \beta \alpha$ topology that harbors five highly conserved motifs (Adenosine, Phosphate-1, Phosphate-2, Connect-1 and Connect-2) [36] (Figure 3). The N- and C- terminal domains of ASKHA superfamily of proteins could be further divided into two subdomains. The $\mathrm{N}$ - and $\mathrm{C}$-terminal conserved subdomains conform to the $\beta \beta \beta \alpha \beta \alpha \beta \alpha$ topology while variable subdomains are constituted by insertions (Figures $3 \mathrm{~A}$ and $\mathrm{B}$ ) that may account for the functional diversity of these proteins. Among acetokinase family, a characteristic insertion corresponding to residues $150-180$ of StAckA is present before $\alpha_{1} 3$ of domain-I (Figures 3A and B). This segment contains a few $\alpha$ - and $3_{10}$-helices, which form part of the dimer interface. Another unique insertion (residues 354-377 of StAckA) in acetate and propionate kinases is found between $\alpha_{\mathrm{II}} 2$ and $\beta_{\mathrm{II}} 5$ of domain-II. In StAckA, the insertion consists of an additional $\beta$-strand $\left(\beta_{\text {II }} \mathrm{a}\right)$ that extends the central $\beta$-sheet, an $\alpha$-helix $\left(\alpha_{\text {II }} g\right)$ and two $3_{10}$ helices $\left(3_{\text {II }} f\right.$ and $\left.3_{\text {II }} f^{*}\right)$. This insertion is not found in butyrate kinase. Also, the sequence of the inserted segment is not well conserved between acetate and propionate kinases. As residues from this region interact with the base of the nucleotide, the insertion may be significant for mechanistic differences within the acetokinase family of enzymes.

\section{Molecular basis of thermal stability in acetokinases}

Availability of several acetokinase structures from mesophilic (Form-I StAckA; S. typhimurium propionate kinase (StTdcD), PDB:2EIY; Francisella tularensis acetate/ propionate kinase (FtTdcD), PDB:3KHY and Mycobacterium avium acetate kinase (MaAckA), PDB:3P4I) as well as thermophilic (MtAckA, PDB:1 G99; Thermotoga maritima acetate kinase (TmAckA), PDB:2IIR and TmBuk2, PDB:1SAZ) organisms in PDB allows analysis of features that might contribute to the enhanced stability of AckA homologs found in thermophiles. Analysis of amino acid composition of these proteins revealed that the protein surfaces in thermophilic AckA homologs have a larger number of charged residues and a smaller number of polar residues when compared to mesophilic counterparts. Solvent exposed surface of thermophilic MtAckA contains 23\% polar, 40\% nonpolar and $37 \%$ charged residues compared to $30 \%$ polar, $39 \%$ non-polar and 31\% charged residues, respectively, of mesophilic StAckA. The increase in charged residues on the surface of the thermophilic proteins results in enhanced intra-subunit ionic interactions (salt bridges: StAckA = 12; $M t$ AckA = 23). Also, an excess of hydrogen bonds $\quad($ StAckA $=23 ; \quad M t$ AckA $=32)$ and salt-bridges $(S t$ AckA $=8 ; M t$ AckA $=19)$ in the dimeric interface provides additional stability to the thermophilic enzymes. Thus, the thermophilic proteins of acetokinase family 
seem to achieve stability by a large number of intra- and inter-subunit ionic interactions.

\section{Domain motion associated with ligand binding}

Superposition of Form-I StAckA with protomers of $M t$ AckA structure (PDB:1TUY) revealed that StAckA is in a conformation intermediate to that of the open and closed states of Methanosarcina enzyme (Figure 5A). In order to gain insights on plausible domain motion, StAckA and MtAckA were subjected to normal mode analysis using the ELastic NEtwork MOdel (ELNEMO) server. The analysis revealed conformations of StAckA that were similar to both the open $\left(C_{\alpha}\right.$ rmsd: $\left.1.15 \AA\right)$ and closed $\left(C_{\alpha}\right.$ rmsd: $\left.1.23 \AA\right)$ states of MtAckA subunits, and in conjunction with fluorescence studies (Figure 5B), suggests that StAckA is also compatible with the inter-domain movements as observed in MtAckA. It is possible that the structure of Form-I StAckA protomer represents an intermediate state in which the active site is accessible to the solvent and ligands. The closed form may represent the active site geometry required for catalysis. The open form may facilitate expulsion of product by reducing the interactions that stabilize the bound ligands.

\section{Implication of dimeric interface pocket for the function of StAckA}

The most intriguing result of the present investigations is the rearrangement and partial disorder observed in a large segment (residues 230-300) of the Form-II polypeptide (Figures 6A and B). Despite the disordered nature, modeled residues of the variable segment possess significant electron density (Additional file 1 Figure S1) and show well restrained stereochemistry [37]. Examination of the electron density revealed the presence of a citrate molecule bound at the dimeric interface (Figures $6 \mathrm{C}$ and 7) and led to the identification of a putative ligand binding pocket in acetokinase family of enzymes (Figure 8 and Additional file 2: Figure S2). AckA is an important enzyme that could play a key role in controlling the flux of metabolites in several pathways including glycolysis, gluconeogenesis, TCA cycle, glyoxylate bypass and fatty acid metabolism [2,3,6-8,10,11]. Examination of the thermal stability of StAckA incubated with $10 \mathrm{mM}$ citrate showed an increase in $\mathrm{T}_{\mathrm{m}}\left(55^{\circ} \mathrm{C}\right)$ by $10^{\circ} \mathrm{C}$ consistent with the binding of the ligand. However, at this concentration of citrate, no change in the activity of StAckA was observed. Therefore, it is possible that some other metabolite of these pathways bind at the putative dimeric interface pocket and regulate the enzyme activity. In this regard, some of the metabolites of TCA cycle and their analogs were tested for inhibition of StAckA, of which malate was found to inhibit the enzyme maximally (Table 1). Further investigations on the nature of inhibition and similar studies with other members of acetokinase family enzymes might reveal the physiological significance of such a ligand-binding pocket.

\section{Conclusions}

Biochemical studies on StAckA suggested that the preferred substrate of the enzyme is acetate. The enzyme showed significant catalytic rates with formate and propionate but did not utilize butyrate as a substrate. The kinetic characterization further revealed broad specificity of the enzyme with respect to nucleotides and metal ions. Structure of Form-I StAckA determined in the present study represents the first report of an unliganded as well as mesophilic AckA. Biophysical studies of StAckA and comparison with other AckA homologs provided insights into the mechanism of ligand binding, domain motion and thermal stability in AckA family of enzymes. In Form-II StAckA, we observed completely unexpected conformational differences in a large segment of the polypeptide between the two forms. This lead to the serendipitous identification of a conserved ligand binding pocket at the dimeric interface of StAckA and its homologs that could form a basis for further mechanistic investigations of this family of enzymes.

\section{Additional files}

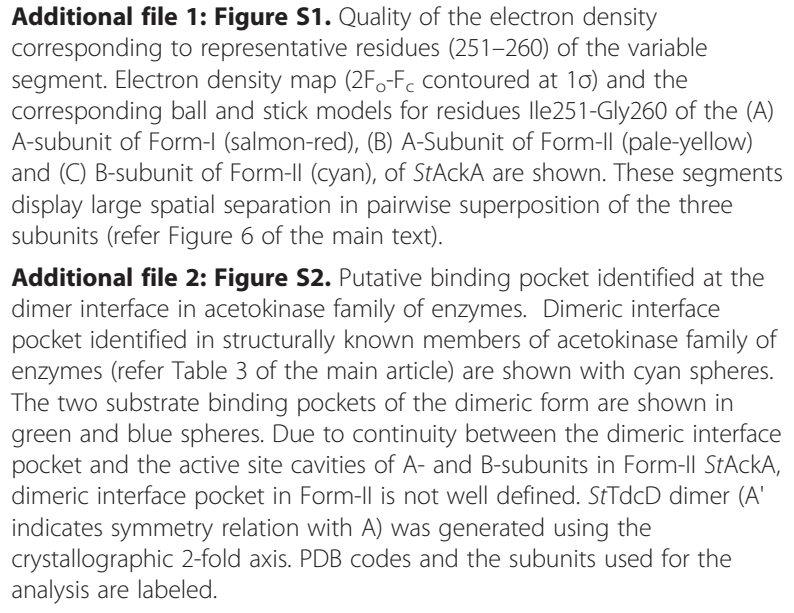

Additional file 2: Figure S2. Putative binding pocket identified at the dimer interface in acetokinase family of enzymes. Dimeric interface pocket identified in structurally known members of acetokinase family of enzymes (refer Table 3 of the main article) are shown with cyan spheres. The two substrate binding pockets of the dimeric form are shown in green and blue spheres. Due to continuity between the dimeric interface pocket and the active site cavities of A- and B-subunits in Form-II StAckA, dimeric interface pocket in Form-II is not well defined. StTdcD dimer ( $A^{\prime}$ indicates symmetry relation with $A$ ) was generated using the crystallographic 2-fold axis. PDB codes and the subunits used for the analysis are labeled.

\section{Abbreviations}

AckA: Acetate kinase; StAckA: Salmonella typhimurium acetate kinase; ASKHA: Acetate and sugar kinases/heat shock cognate (Hsc) 70/Actin.

\section{Competing interests}

The authors declare that they have no competing interests.

\section{Authors' contributions}

MRN and HSS conceived and supervised the project. SC performed the experiments, analyzed the data and wrote the paper. All authors have read and approved the final manuscript. 


\section{Acknowledgements}

The authors would like to thank James and Babu of X-ray facility at the Molecular Biophysics Unit, Indian Institute of Science (IISC), and Dr. Hassan Belrhali and Dr. Babu Manjasetty of beamline BM14 at European Synchrotron Radiation Facility (ESRF), France for the assistance during X-ray diffraction data collection. We thank Chhavi Mathur for critical reading of the manuscript. This work was supported by the Department of Science and Technology (DST) [grant number SR/SO/BB-47/2009 (to MRN and HSS)] and Department of Biotechnology (DBT) [grant number BT/PR10912/BRB/10/630/ 2008 (to MRN and HSS)], Government of India; the Council for Scientific and Industrial Research (CSIR), Government of India, and IISC fellowships to SC.

\section{Author details}

'Molecular Biophysics Unit, Indian Institute of Science, Bangalore, Karnataka 560012, India. 'Department of Biochemistry, Indian Institute of Science, Bangalore, Karnataka 560012, India. ${ }^{3}$ Current address: Laboratory of Cellular and Molecular Neurophysiology, Porter Neuroscience Research Center, NICHD, NIH, DHHS, Bethesda, MD 20892, USA.

Received: 17 June 2012 Accepted: 24 September 2012

Published: 2 October 2012

\section{References}

1. Cortay JC, Bleicher F, Duclos B, Cenatiempo Y, Gautier C, Prato JL, Cozzone AJ: Utilization of acetate in Escherichia coli: structural organization and differential expression of the ace operon. Biochimie 1989, 71(9-10):1043-1049.

2. Nunn WD: A molecular view of fatty acid catabolism in Escherichia coli. Microbiol Rev 1986, 50(2):179-192.

3. Wolfe AJ: The acetate switch. Microbiol Mol Biol Rev 2005, 69(1):12-50.

4. Brown TD, Jones-Mortimer MC, Kornberg HL: The enzymic interconversion of acetate and acetyl-coenzyme A in Escherichia coli. J Gen Microbiol 1977, 102(2):327-336.

5. Rose IA, Grunberg-Manago M, Korey SR, Ochoa S: Enzymatic phosphorylation of acetate. J Biol Chem 1954, 211(2):737-756.

6. McCleary WR, Stock JB, Ninfa AJ: Is acetyl phosphate a global signal in Escherichia coli? J Bacteriol 1993, 175(10):2793-2798.

7. Wolfe AJ, Chang DE, Walker JD, Seitz-Partridge JE, Vidaurri MD, Lange CF, Prüss BM, Henk MC, Larkin JC, Conway T: Evidence that acetyl phosphate functions as a global signal during biofilm development. Mol Microbiol 2003, 48(4):977-988

8. Fox DK, Meadow ND, Roseman S: Phosphate transfer between acetate kinase and enzyme I of the bacterial phosphotransferase system. J Biol Chem 1986, 261(29):13498-13503.

9. Fox DK, Roseman S: Isolation and characterization of homogeneous acetate kinase from Salmonella typhimurium and Escherichia coli. J Biol Chem 1986, 261(29):13487-13497.

10. Ingram-Smith C, Martin SR, Smith KS: Acetate kinase: not just a bacterial enzyme. Trends Microbiol 2006, 14(6):249-253.

11. Wanner BL, Wilmes-Riesenberg MR: Involvement of phosphotransacetylase, acetate kinase, and acetyl phosphate synthesis in control of the phosphate regulon in Escherichia coli. J Bacteriol 1992, 174(7):2124-2130.

12. Cheek S, Ginalski $\mathrm{K}$, Zhang $H$, Grishin NV: A comprehensive update of the sequence and structure classification of kinases. BMC Struct Biol 2005, 5:6.

13. Simanshu DK, Savithri HS, Murthy MR: Crystal structures of ADP and AMPPNP-bound propionate kinase (TdcD) from Salmonella typhimurium: comparison with members of acetate and sugar kinase/heat shock cognate 70/actin superfamily. J Mol Biol 2005, 352(4):876-892.

14. Li RD, Li YY, Lu LY, Ren C, Li YX, Liu L: An improved kinetic model for the acetone-butanol-ethanol pathway of Clostridium acetobutylicum and model-based perturbation analysis. BMC Syst Biol 2011, 5(Suppl 1):S12.

15. Buss KA, Cooper DR, Ingram-Smith C, Ferry JG, Sanders DA, Hasson MS: Urkinase: structure of acetate kinase, a member of the ASKHA superfamily of phosphotransferases. J Bacteriol 2001, 183(2):680-686.

16. Gorrell A, Lawrence SH, Ferry JG: Structural and kinetic analyses of arginine residues in the active site of the acetate kinase from Methanosarcina thermophila. J Biol Chem 2005, 280(11):10731-10742

17. Chittori S, Savithri HS, Murthy MR: Preliminary X-ray crystallographic studies on acetate kinase (AckA) from Salmonella typhimurium in two crystal forms. Acta Crystallogr Sect F Struct Biol Cryst Commun 2011, 67(Pt 12):1658-1661.

18. Emsley P, Cowtan K: Coot: model-building tools for molecular graphics. Acta Crystallogr D Biol Crystallogr 2004, 60(Pt 12):2126-2132.

19. Murshudov GN, Vagin AA, Dodson EJ: Refinement of macromolecular structures by the maximum-likelihood method. Acta Crystallogr D Biol Crystallogr 1997, 53(Pt 3):240-255.

20. Bairoch A, Boeckmann B: The SWISS-PROT protein sequence data bank. Nucleic Acids Res 1992, 20(Suppl):2019-2022.

21. Holm L, Sander C: Dali: a network tool for protein structure comparison. Trends Biochem Sci 1995, 20(11):478-480.

22. Thompson JD, Higgins DG, Gibson TJ: CLUSTAL W: improving the sensitivity of progressive multiple sequence alignment through sequence weighting, position-specific gap penalties and weight matrix choice. Nucleic Acids Res 1994, 22(22):4673-4680.

23. Gouet P, Robert $X$, Courcelle E: ESPript/ENDscript: Extracting and rendering sequence and $3 \mathrm{D}$ information from atomic structures of proteins. Nucleic Acids Res 2003, 31(13):3320-3323.

24. Krissinel E, Henrick K: Inference of macromolecular assemblies from crystalline state. J Mol Biol 2007, 372(3):774-797.

25. Reynolds C, Damerell D, Jones S: ProtorP: a protein-protein interaction analysis server. Bioinformatics 2009, 25(3):413-414.

26. Emekli U, Schneidman-Duhovny D, Wolfson HJ, Nussinov R, Haliloglu T: HingeProt: automated prediction of hinges in protein structures. Proteins 2008, 70(4):1219-1227.

27. Suhre $K$, Sanejouand YH: EINemo: a normal mode web server for protein movement analysis and the generation of templates for molecular replacement. Nucleic Acids Res 2004, 32(Web Server issue):W610-W614.

28. Dundas J, Ouyang Z, Tseng J, Binkowski A, Turpaz Y, Liang J: CASTp: computed atlas of surface topography of proteins with structural and topographical mapping of functionally annotated residues. Nucleic Acids Res 2006, 34(Web Server issue):W116-W118.

29. Brünger AT, Adams PD, Clore GM, DeLano WL, Gros P, Grosse-Kunstleve RW, Jiang JS, Kuszewski J, Nilges M, Pannu NS, Read RJ, Rice LM, Simonson T, Warren GL: Crystallography \& NMR system: A new software suite for macromolecular structure determination. Acta Crystallogr D Biol Crystallogr 1998, 54(Pt 5):905-921.

30. Bennett WS Jr, Steitz TA: Glucose-induced conformational change in yeast hexokinase. Proc Natl Acad Sci USA 1978, 75(10):4848-4852.

31. Schnick C, Polley SD, Fivelman QL, Ranford-Cartwright LC, Wilkinson SR, Brannigan JA, Wilkinson AJ, Baker DA: Structure and non-essential function of glycerol kinase in Plasmodium falciparum blood stages. Mol Microbiol 2009, 71(2):533-545.

32. van den Ent F, Møller-Jensen J, Amos LA, Gerdes K, Löwe J: F-actin-like filaments formed by plasmid segregation protein ParM. EMBO J 2002, 21(24):6935-6943.

33. Gorrell A, Ferry JG: Investigation of the Methanosarcina thermophila acetate kinase mechanism by fluorescence quenching. Biochemistry 2007 , 46(49):14170-14176.

34. Chhabra G, Sharma P, Anant A, Deshmukh S, Kaushik H, Gopal K Srivastava N, Sharma N, Garg LC: Identification and modeling of a drug target for Clostridium perfringens SM101. Bioinformation 2010 4(7):278-289.

35. Simanshu DK, Savithri HS, Murthy MR: Crystal structures of Salmonella typhimurium propionate kinase and its complex with Ap4A: evidence for a novel Ap4A synthetic activity. Proteins 2008, 70(4):1379-1388.

36. Bork P, Sander C, Valencia A: An ATPase domain common to prokaryotic cell cycle proteins, sugar kinases, actin, and hsp70 heat shock proteins. Proc Natl Acad Sci USA 1992, 89(16):7290-7294.

37. Laskowski RA, MacArthur MW, Moss DS, Thornton JM: PROCHECK - a program to check the stereochemical quality of protein structures. J App Cryst 1993, 26(2):283-291.

doi:10.1186/1472-6807-12-24

Cite this article as: Chittori et al: Structural and mechanistic investigations on Salmonella typhimurium acetate kinase (AckA): identification of a putative ligand binding pocket at the dimeric interface. BMC Structural Biology 2012 12:24. 